\title{
Predictors of progression to chronic dialysis in survivors of severe acute kidney injury: a competing risk study
}

Ziv Harel ${ }^{1,2^{*}}$, Chaim M Bell ${ }^{3}$, Stephanie N Dixon ${ }^{4,5}$, Eric McArthur ${ }^{4,5}$, Matthew T James ${ }^{6}$, Amit X Garg ${ }^{4,5}$, Shai Harel ${ }^{1}$, Samuel Silver ${ }^{1}$ and Ron Wald ${ }^{1,2}$

\begin{abstract}
Background: Survivors of acute kidney injury are at an increased risk of developing irreversible deterioration in kidney function and in some cases, the need for chronic dialysis. We aimed to determine predictors of chronic dialysis and death among survivors of dialysis-requiring acute kidney injury.

Methods: We used linked administrative databases in Ontario, Canada, to identify patients who were discharged from hospital after an episode of acute kidney injury requiring dialysis and remained free of further dialysis for at least 90 days after discharge between 1996 and 2009. Follow-up extended until March 31, 2011. The primary outcome was progression to chronic dialysis. Predictors for this outcome were evaluated using cause-specific Cox proportional hazards models, and a competing risk approach was used to calculate absolute risk.

Results: We identified 4383 patients with acute kidney injury requiring temporary in-hospital dialysis who survived to discharge. After a mean follow-up of 2.4 years, 356 (8\%) patients initiated chronic dialysis and 1475 (34\%) died. The cumulative risk of chronic dialysis was $13.5 \%$ by the Kaplan-Meier method, and $10.3 \%$ using a competing risk approach. After accounting for the competing risk of death, previous nephrology consultation (subdistribution hazard ratio (sHR) 2.03; 95\% confidence interval (Cl) 1.61-2.58), a history of chronic kidney disease (sHR3.86; 95\% Cl 2.99-4.98), a higher Charlson comorbidity index score (sHR 1.10; 95\% Cl 1.05-1.15/per unit) and pre-existing hypertension (sHR 1.82; 95\% Cl 1.28-2.58) were significantly associated with an increased risk of progression to chronic dialysis.

Conclusions: Among survivors of dialysis-requiring acute kidney injury who initially become dialysis independent, the subsequent need for chronic dialysis is predicted by pre-existing kidney disease, hypertension and global comorbidity. This information can identify patients at high risk of progressive kidney disease who may benefit from closer surveillance after cessation of the acute phase of illness.
\end{abstract}

Keywords: Acute kidney injury, Predictors, Chronic dialysis, Competing risk

\section{Background}

Acute kidney injury (AKI) is a common and serious complication of hospitalization; in severe cases, urgent renal replacement therapy (hereafter referred to as dialysis) is needed to address complications of AKI and to support the patient in overcoming the acute illness. Between 2000

\footnotetext{
* Correspondence: harelz@smh.ca

'Division of Nephrology, St Michael's Hospital, University of Toronto, 61 Queen Street, 7th floor, M5C 2 T2, ON Toronto, Canada

${ }^{2}$ Department of Medicine and Keenan Research Centre, Li Ka Shing Knowledge Institute of St Michael's Hospital, University of Toronto, Toronto, Canada

Full list of author information is available at the end of the article
}

and 2009, the incidence of dialysis requiring AKI (AKI-D) in the United States increased by $10 \%$ annually from 222 to 533 cases per million person-years [1]. The increased incidence of AKI will result in greater numbers of patients who are faced with persistent health challenges after the acute phase of their illness has resolved. As a result, acquisition of a better understanding of AKI survivors, who are at increased risk of progressive kidney disease, and death, is of vital public health importance [2-5].

Recognition that survivors of AKI are at high risk of progressive chronic kidney disease (CKD) spurred the Kidney Disease Improving Global Outcomes (KDIGO) 
AKI guidelines to recommended that kidney function should be evaluated 3 months after an AKI episode to establish the presence and extent of chronic kidney disease [6] However, others have advocated that Nephrology follow-up occur for all patients with severe AKI [7]. With almost 1 in 5 adults worldwide experiencing an episode of AKI during a hospitalization, two percent of whom require dialysis, such a broad referral strategy may be impractical [8]. Identifying AKI-D survivors at the greatest risk of progressive CKD would potentially lead to the targeted follow-up for individuals who are most likely to realize a benefit. Accordingly, in a cohort of AKI-D survivors, we performed a study to determine the predictors of permanent maintenance dialysis and secondarily, death.

\section{Methods}

\section{Design and participants}

We conducted a retrospective study using populationwide linked administrative health databases for all of Ontario, Canada. We identified Ontario residents aged 19 years and older admitted to an acute care hospital between April 1, 1996 and March 31, 2009, for whom length of stay was less than 180 days. We focused on individuals who had a diagnosis of AKI and a claim for acute dialysis during a hospital stay, and lived for at least 90 days after hospital discharge without re-initiation of dialysis or rehospitalization during this 90-day period. We excluded individuals with a previous diagnosis of AKI, receipt of a kidney transplant, or any form of dialysis in the 5-year period preceding the index hospitalization. Ontario is Canada's most populous province, and all residents are covered by a government-funded universal healthcare program. No informed written consent was obtained from each individual included in our study as administrative data was used. The study was approved by the research ethics board of Sunnybrook Hospital.

\section{Data sources}

The study was completed using linked records from six administrative health care databases using encrypted unique identifiers. Hospitalization records were obtained from the Canadian Institute for Health Information Discharge Abstract Database (DAD), which was used to identify an acute hospitalization, the presence of AKI, as well as inpatient comorbidities and procedural information on the basis of codes from the International Classification of Diseases (ICD 9th or 10th Revision). The Ontario Health Insurance Plan (OHIP) database provided information on physician claims for inpatient and outpatient services, including dialysis. (Additional file 1) The Ontario Registered Persons Database contained basic demographic information for each eligible individual including date of death. Income quintile was based on postal codes for residence area as outlined in the 2001 Statistics Canada Census. Permission to use these databases was granted by the research ethics board of Sunnybrook Hospital.

\section{Candidate variable definitions}

Candidate variables were selected based on review of the literature and clinical relevance and encompassed demographics, comorbidities, features of the index hospitalization, and markers of health services utilization. (Additional file 1) All demographic, comorbidity, and health care utilization covariates were ascertained from 5 years preceding the hospital discharge date except chronic kidney disease which had a lookback period of 5 years preceding the hospital admission date. Similar to previous studies, we included both the Charlson comorbidity index score and the individual components of the score in our model, including chronic kidney disease. The Charlson comorbidity score is a validated method for estimating the risk of death from comorbid disease, and has been used in multiple studies [9]. Each comorbid condition included in the Charlson index is assigned a score of $1,2,3$, or 6 , depending on the risk of dying associated with each condition [9]. The individual scores are summed to provide a total comorbidity score (Charlson comorbidity score) to predict mortality. A standard algorithm proposed by Quan et al. was used to define the Charlson comorbidity score using the DAD [10]. In line with previous studies, we defined CKD using administrative coding (see Additional file 2 for codes), which is highly specific but poorly sensitive (median sensitivity $41 \%$; median specificity 98\%) $[4,11]$.

\section{Outcomes}

The period of follow-up commenced at day 90 following discharge for all patients. This period is in line with that used in other AKI follow-up studies in order to mitigate bias that may be attributed to the high mortality rate after discharge among patients with AKI who require temporary renal replacement therapy likely as a result of the underlying illness that mediated the AKI [11-13]. The main outcome was chronic dialysis, which was defined as the receipt of dialysis for at least 90 days [4]. This definition is widely accepted and has been used in multiple studies of AKI $[4,5,11]$. The date of the first dialysis claim was considered to be the date of initiation of dialysis. The secondary outcome was all-cause mortality.

\section{Statistical analyses}

Baseline characteristics of the study participants were summarized using descriptive statistics. Continuous variables were expressed as mean (SD) or median (interquartile range [IQR]) and compared using the unpaired t-test or Kruskal-Wallis test, respectively. Categorical variables were expressed as a percentage and compared using a $\chi^{2}$ test or Fisher's exact test. 


\section{Cause specific Cox hazard model and competing risk analysis}

The associations between baseline covariates and outcomes were assessed using Cox proportional hazards regression. For the primary outcome of chronic dialysis, subjects were censored in the event of death or at the conclusion of follow-up, March 31, 2011. For the all-cause mortality outcome, subjects were censored at the conclusion of the follow-up, March 31, 2011.

Candidate variables that were associated with the outcome of interest $(\mathrm{P} \leq .10)$ on univariate analysis and those that were deemed to be clinically important regardless of statistical significance were included as potential covariates in the multivariable Cox proportional hazards models. The presence of collinearity within the models was examined by evaluation of variance inflation factors. Timedependent variables were created to evaluate whether the proportional hazards assumption was met. In cases where the proportional hazards assumption was not met, the candidate variable was modeled as a time-dependent covariate.

As death was a competing risk for the receipt of chronic dialysis, using the method of Fine and Gray, we also developed a semiparametric Cox proportional hazards model that estimated the risk of chronic dialysis initiation with death considered as a competing risk [14].

The standard Cox model and the competing risk approach differ in the way absolute risk predictions are calculated. Whereas predictions from the standard Cox model depend only on the cause-specific hazard of the event of interest (receipt of chronic dialysis) and thus overestimate absolute risk in the presence of a competing event (death), the competing risk approach consists of developing a cause-specific hazards models for both the event of interest (the receipt of chronic dialysis) and the competing event (death) separately, and then combining them according to the cumulative incidence function [15].

\section{Model performance}

Model discrimination for each of the cause-specific Cox hazard models (chronic dialysis and all-cause mortality) was assessed for discrimination using the Harrell global C-statistic.

Baseline comparisons and development of cause-specific Cox proportional hazards models were performed using SAS version 9.1 for UNIX (SAS Institute, Cary, NC), and the competing risk model was developed using $\mathrm{R}$ version 2.9.1 (R Foundation for Statistical Computing, Vienna, Austria).

\section{Results}

\section{Characteristics of study participants}

We identified 4383 patients with a previous episode of AKI-D who survived to 90 days following hospital discharge with no reinitiation of dialysis. (Figure 1) Mean age was $61( \pm 16)$ years, $60 \%$ were male and $28 \%$ had seen

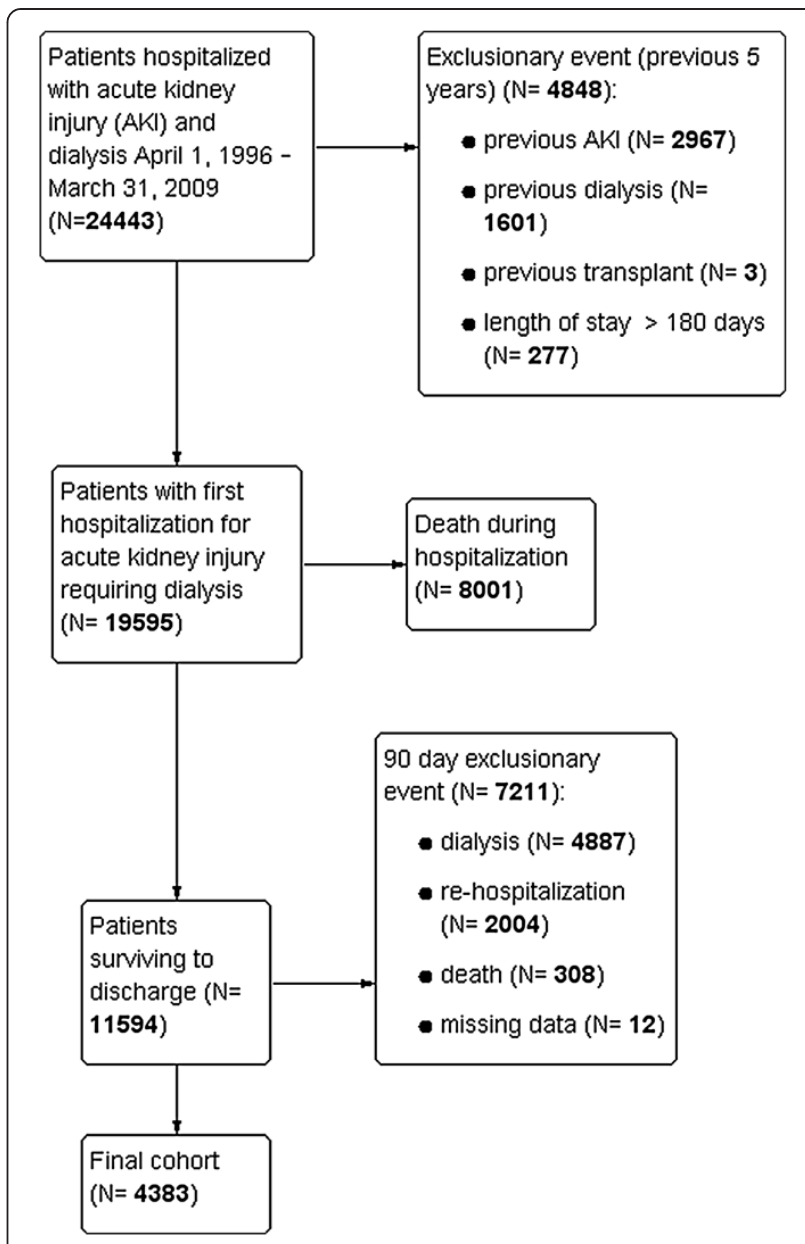

Figure 1 Cohort creation.

a nephrologist prior to the index hospitalization on which the AKI-D occurred. The median Charlson comorbidity score was 3 (IQR 1-4). The prevalence of pre-existing coronary artery disease, diabetes, chronic kidney disease, and cancer were $49 \%, 44 \%, 17.2 \%$, and $39 \%$ respectively.

Patients who progressed to chronic dialysis $(\mathrm{n}=356$, $8.1 \%$ of cohort ) were older (64 vs. 61 years in patients with no progression to chronic dialysis, $\mathrm{p}<0.01$ ), had a higher likelihood of previous visit to a nephrologist (60\% vs. $25 \%, \mathrm{p}<0.01)$ and cardiologist ( $61 \%$ vs. $46 \%, \mathrm{p}<0.01)$, and had a higher burden of comorbid disease (including cardiac disease ( $59 \%$ vs. $48 \%, \mathrm{p}<0.01)$, congestive heart failure ( $54 \%$ vs. $36 \%, \mathrm{p}<0.01)$, diabetes ( $61 \%$ vs. $43 \%, \mathrm{p}<0.01)$, hypertension $(87 \%$ vs. $68 \%, \mathrm{p}<0.01)$, peripheral vascular disease ( $6 \%$ vs. $3 \%, \mathrm{p}<0.01)$, cancer $(43 \%$ vs. $39 \%, \mathrm{p}<0.01)$, and chronic kidney disease ( $57 \%$ vs. $14 \%, \mathrm{p}<0.01)$ ) than those who did not progress to chronic dialysis ( $\mathrm{n}=$ $4,027)$. On the other hand, individuals who progressed to chronic dialysis were significantly less likely to require mechanical ventilation ( $46 \%$ vs. $59 \%, \mathrm{p}<0.01$ ), or have a diagnosis of sepsis during their index admission (14\% vs. $20 \%$, p < 0.01) (Table 1$)$. 
Table 1 Baseline characteristics of the cohort stratified by progression to chronic dialysis

\begin{tabular}{|c|c|c|c|}
\hline Variable & $\begin{array}{l}\text { Chronic dialysis } \\
\qquad N=356\end{array}$ & $\begin{array}{l}\text { No chronic dialysis } \\
\qquad N=4,027\end{array}$ & p-value \\
\hline \multicolumn{4}{|l|}{ Demographics and health utilization } \\
\hline Age, mean (SD) & $64( \pm 14)$ & $61( \pm 17)$ & $<0.01$ \\
\hline Female gender, $\mathrm{n}(\%)$ & $143(40)$ & $1629(41)$ & 0.92 \\
\hline Rural locale & $53(15)$ & $548(14)$ & 0.58 \\
\hline Pre-admission nephrology consultation, n (\%) & $213(60)$ & $1004(25)$ & $<0.01$ \\
\hline Pre-admission cardiology consultation, n (\%) & $216(61)$ & $1835(46)$ & $<0.01$ \\
\hline \multicolumn{4}{|l|}{ Comorbid disease } \\
\hline Charlson comorbidity score, median (IQR) & $4(2-6)$ & $2(1-4)$ & $<0.01$ \\
\hline Coronary artery disease, n (\%) & $209(59)$ & $1933(48)$ & $<0.01$ \\
\hline Congestive heart failure, $\mathrm{n}(\%)$ & $191(54)$ & $1439(36)$ & $<0.01$ \\
\hline Cerebrovascular disease, n (\%) & $63(18)$ & $713(18)$ & 1 \\
\hline Diabetes, n (\%) & $218(61)$ & $1712(43)$ & $<0.01$ \\
\hline Malignancy, n (\%) & $153(43)$ & $1560(39)$ & 0.12 \\
\hline Liver disease, n (\%) & $27(8)$ & $644(16)$ & $<0.01$ \\
\hline Peripheral vascular disease, n (\%) & $21(6)$ & $115(3)$ & $<0.01$ \\
\hline Chronic kidney disease, n (\%) & $204(57)$ & $551(14)$ & $<0.01$ \\
\hline Hypertension, n (\%) & $309(87)$ & $2738(68)$ & $<0.01$ \\
\hline Dementia, n (\%) & $25(7)$ & $334(8)$ & 0.40 \\
\hline Proteinuria, n (\%) & $9(3)$ & $13(0.3)$ & $<0.01$ \\
\hline Hematuria, n (\%) & $125(35)$ & $1060(26)$ & $<0.01$ \\
\hline \multicolumn{4}{|l|}{ Conditions during index hospitalization } \\
\hline Sepsis, n (\%) & $49(14)$ & $807(20)$ & $<0.01$ \\
\hline Aortic aneurysm repair, n (\%) & $10(3)$ & $155(4)$ & 0.32 \\
\hline Cardiac surgery, n (\%) & $10(3)$ & $155(4)$ & 0.32 \\
\hline Mechanical ventilation, n (\%) & $163(46)$ & $2209(55)$ & $<0.01$ \\
\hline \multicolumn{4}{|l|}{ Hospital type } \\
\hline Teaching Hospital, n (\%) & $173(49)$ & $1980(49)$ & 0.84 \\
\hline
\end{tabular}

an the 5 years preceding hospital admission.

${ }^{\mathrm{b}}$ In the 5 years preceding the hospital discharge date except chronic kidney disease which had a lookback period of 5 years preceding the hospital admission date.

Patients who died during the study follow-up $(\mathrm{n}=$ $1,475,33.7 \%$ of total cohort) were older (68 vs. 56 years, $\mathrm{p}<0.01)$, more likely to have seen a nephrologist $(30 \%$ vs. $22 \%, \mathrm{p}<0.01$ ), and had a higher prevalence of preexisiting comorbidities (including cardiac disease $(57 \%$ vs. $43 \%, \mathrm{p}<0.01)$, congestive heart failure $(49 \%$ vs. $28 \%$, $\mathrm{p}<0.01$ ), diabetes ( $48 \%$ vs. $40 \%, \mathrm{p}<0.01)$, cancer ( $49 \%$ vs. $33 \%, \mathrm{p}<0.01)$, chronic kidney disease (19\% vs. $10 \%$, $\mathrm{p}<$ 0.01 ), and hypertension (76\% vs. 63\%, p < 0.01) (Table 2).

\section{Outcomes}

After a mean follow-up of 2.4 years, the cumulative incidence of chronic dialysis was $13.5 \%$ by the KaplanMeier method, and $10.3 \%$ using the competing risk approach. (Figure 2) The cumulative incidence of allcause mortality was $54.2 \%$, after a mean follow-up of 3.0 years, and 1475 patients died prior to the initiation of chronic dialysis therapy.

\section{Predictors of chronic dialysis}

Previous nephrology consultation (adjusted hazard ratio (aHR) 2.12, 95\% CI 1.67-2.70), Charlson comorbidity score (aHR 1.17; 95\% CI 1.11-1.24 per unit increase), a history of chronic kidney disease (aHR 4.04, 95\% CI 3.14-5.2), and pre-existing hypertension (aHR 1.70; 95\% CI 1.21-2.37) were significantly associated with an increased risk of chronic dialysis. Prior liver disease (aHR 0.42 ; 95\% CI 0.28-0.63) and the receipt of mechanical ventilation on the index hospitalization (aHR 0.78; 95\% CI 0.62-0.97) were inversely associated with chronic dialysis. (Table 3) The c-statistics for the chronic dialysis model using the cause-specific Cox approach was 0.66 (95\% CI 0.62-0.71). 
Table 2 Baseline characteristics of the cohort stratified by death during the follow-up period

\begin{tabular}{|c|c|c|c|}
\hline Variable & $\begin{array}{c}\text { Death } \\
N=1,475\end{array}$ & $\begin{array}{c}\text { Alive } \\
\mathrm{N}=2.908\end{array}$ & p-value \\
\hline \multicolumn{4}{|l|}{ Demographics and health utilization } \\
\hline Age, mean (SD) & $68( \pm 14)$ & $56( \pm 17)$ & $<0.01$ \\
\hline Female gender, $\mathrm{n}(\%)$ & $589(40)$ & $1040(41)$ & 0.61 \\
\hline Rural locale, n (\%) & $206(14)$ & $395(14)$ & 0.73 \\
\hline Pre-admission nephrology consultation, $\mathrm{n}(\%)^{\mathrm{a}}$ & $441(30)$ & $563(22)$ & $<0.01$ \\
\hline Pre-admission cardiology consultation, $\mathrm{n}(\%)^{\mathrm{a}}$ & $750(51)$ & $1085(43)$ & $<0.01$ \\
\hline \multicolumn{4}{|l|}{ Comorbid disease $e^{b}$} \\
\hline Charlson comorbidity score, median (IQR) & $4(2-5)$ & $2(0-3)$ & $<0.01$ \\
\hline Coronary artery disease, n (\%) & $842(57)$ & $1091(43)$ & $<0001$ \\
\hline Congestive heart failure, $\mathrm{n}(\%)$ & $718(49)$ & $721(28)$ & $<0.01$ \\
\hline Cerebrovascular disease, n (\%) & $349(24)$ & $364(14)$ & $<0.01$ \\
\hline Diabetes, n (\%) & $700(48)$ & $1012(40)$ & 0.08 \\
\hline Malignancy, n (\%) & $715(49)$ & $845(33)$ & $<0.01$ \\
\hline Liver disease, n (\%) & $214(15)$ & $430(17)$ & 0.05 \\
\hline Peripheral vascular disease, n (\%) & $82(6)$ & $33(1)$ & $<0.01$ \\
\hline Chronic kidney disease, n (\%) & $286(19)$ & $265(10)$ & $<0.01$ \\
\hline Hypertension, n (\%) & $1122(76)$ & $1616(63)$ & $<0.01$ \\
\hline Dementia, n (\%) & $182(12)$ & $152(6)$ & $<0.01$ \\
\hline Hematuria, n (\%) & $457(31)$ & $603(24)$ & 0.5 \\
\hline Proteinuria, n (\%) & $6(0.4)$ & $7(03)$ & $<0.01$ \\
\hline \multicolumn{4}{|l|}{ Conditions during index hospitalization } \\
\hline Sepsis, n (\%) & $280(19)$ & $527(21)$ & 0.2 \\
\hline Aortic aneurysm repair, n (\%) & $69(5)$ & $86(3)$ & 0.04 \\
\hline Cardiac surgery, n (\%) & $152(10)$ & $320(13)$ & 0.03 \\
\hline Mechanical ventilation, n (\%) & $705(48)$ & $1504(59)$ & $<0.01$ \\
\hline \multicolumn{4}{|l|}{ Hospital type } \\
\hline Teaching hospital, n (\%) & $746(48)$ & $1406(51)$ & 0.15 \\
\hline
\end{tabular}

an the 5 years preceding hospital admission.

${ }^{b}$ In the 5 years preceding the hospital discharge date except chronic kidney disease which had a lookback period of 5 years preceding the hospital admission date.

\section{Predictors of mortality}

Older age (aHR 1.03; 95\% CI 1.02-1.04 per year), Charlson comorbidity score (aHR 1.21; 95\% CI 1.18-1.23 per unit increase in the score), heart failure (aHR 1.18; 95\% CI 1.05-1.33), peripheral vascular disease (aHR 1.32; 95\% CI 1.05-1.66), and dementia (aHR 1.30; 95\% CI 1.10-1.50) were significantly associated with a higher risk of death. Pre-existing diabetes (aHR 0.87; 95\% CI 0.77-0.97), and the receipt of mechanical ventilation during the index hospitalization (aHR 0.79; 95\% CI 0.71-0.87), were associated with a lower risk of death. (Table 3) The c-statistics for the all-cause mortality models using the cause-specific Cox approach was 0.71 (95\% CI 0.67-0.76).

\section{Competing risk approach}

In multivariable analysis using a Fine and Gray regression model that treated death as a competing event, a history of chronic kidney disease (sHR 3.86; 95\% CI 2.994.98), a history of previous nephrology consultation (subdistribution hazard ratio (sHR) 2.03, 95\% CI 1.61-2.58), Charlson comorbidity index score (sHR 1.10; 95\% CI 1.051.15), and hypertension (sHR 1.82; 95\% CI 1.28- 2.58) were significantly associated with the need for chronic dialysis initiation. The presence of liver disease (sHR 0.43; 95\% CI 0.29-0.64) was significantly associated with a lower risk for the initiation of chronic dialysis (Table 4).

\section{Discussion}

Escalating comorbidity, pre-existing kidney disease, as reflected by a diagnosis of CKD or a visit to a nephrologist, and pre-existing hypertension predicted progression to chronic dialysis in a cohort of patients who survived an episode of dialysis-requiring AKI. Similarly, increasing age, a higher Charlson comorbidity score; the presence 


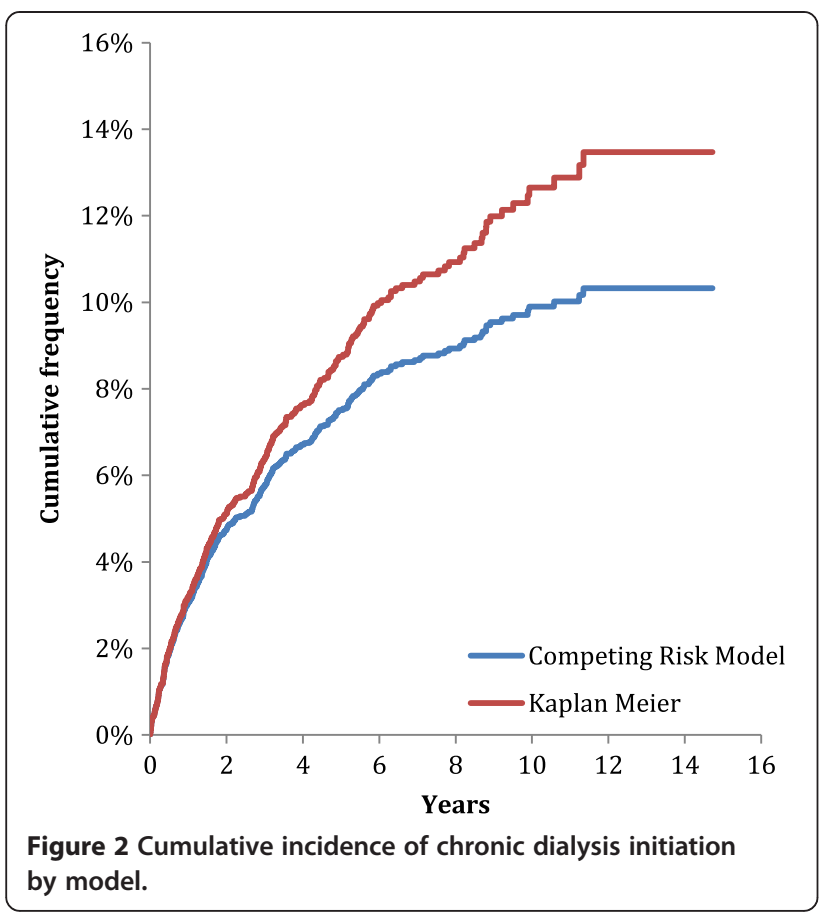

of heart failure, diabetes and dementia were predictive of post-AKI mortality.

Although the link between AKI and subsequent CKD has been extensively described, patients with the most severe form of AKI who require acute dialysis are the

Table 3 Multivariable-adjusted cause-specific hazards ratio for chronic dialysis and all-cause mortality

\begin{tabular}{|c|c|c|}
\hline \multirow[t]{2}{*}{ Variables } & \multicolumn{2}{|c|}{ Hazard ratios $(95 \% \mathrm{Cl})$} \\
\hline & $\begin{array}{l}\text { Chronic } \\
\text { dialysis }\end{array}$ & $\begin{array}{l}\text { All-cause } \\
\text { mortality }\end{array}$ \\
\hline Age & $0.99(0.99-1.00)$ & $1.03(1.02-1.04)^{*}$ \\
\hline Female gender & $0.95(0.76-1.18)$ & $0.91(0.82-1.01)$ \\
\hline Previous nephrology consultation & $2.12(1.67-2.70)^{*}$ & $1.02(0.91-1.16)$ \\
\hline Charlson comorbidity index & $1.17(1.11-1.24)^{*}$ & $1.21(1.18-1.23)^{*}$ \\
\hline Coronary artery disease & $0.86(0.67-1.10)$ & $0.92(0.82-1.03)$ \\
\hline Congestive heart failure & $1.22(0.96-1.56)$ & $1.18(1.05-1.33)^{*}$ \\
\hline Diabetes & $1.15(0.0 .91-1.46)$ & $0.87(0.77-0.97)^{*}$ \\
\hline Liver disease & $0.42(0.28-0.63)^{*}$ & $1.07(0.92-1.25)$ \\
\hline Peripheral vascular disease & $1.03(0.66-1.62)$ & $1.32(1.05-1.66)$ \\
\hline Chronic kidney disease & $4.04(3.14-5.20)^{*}$ & $1.01(0.87-1.17)$ \\
\hline Hypertension & $1.70(1.21-2.37)^{*}$ & $0.93(0.82-1.06)$ \\
\hline Dementia & $-1-$ & $1.30(1.10-1.50)^{*}$ \\
\hline Hematuria & $1.10(0.88-1.37)$ & $1.10(0.99-1.23)$ \\
\hline Proteinuria & $1.85(0.94-3.67)$ & - - \\
\hline Sepsis & $0.84(0.62-1.15)$ & -—- \\
\hline $\begin{array}{l}\text { Receipt of mechanical ventilation } \\
\text { during index admission }\end{array}$ & $0.78(0.62-0.97)^{*}$ & $0.79(0.71-0.87)^{*}$ \\
\hline
\end{tabular}

Table 4 Multivariable model for initiation of chronic dialysis using the competing risk approach

\begin{tabular}{lc}
\hline Variable & $\begin{array}{c}\text { Subdistribution hazard } \\
\text { ratios }(95 \% \mathrm{Cl})\end{array}$ \\
\hline Age & $0.99(0.98-1.00)$ \\
Female gender & $0.95(0.77-1.18)$ \\
Previous nephrology consultation & $2.03(1.61-2.58)^{*}$ \\
Charlson comorbidity index & $1.10(1.05-1.15)^{*}$ \\
Coronary artery disease & $0.87(0.67-1.13)$ \\
Congestive heart failure & $1.21(0.94-1.56)$ \\
Diabetes & $1.18(0.93-1.51)$ \\
Liver disease & $0.43(0.29-0.64)^{*}$ \\
Peripheral vascular disease & $0.90(0.56-1.46)$ \\
Chronic kidney disease & $3.86(2.99-4.98)^{*}$ \\
Hypertension & $1.82(1.28-2.58)^{*}$ \\
Hematuria & $1.06(0.84-1.33)$ \\
Proteinuria & $2.13(0.92-4.97)$ \\
Sepsis & $0.83(0.61-1.13)$ \\
Receipt of mechanical ventilation & $0.85(0.68-1.05)$ \\
during index admission & \\
\hline${ }^{*} \mathrm{p}<0.05$. &
\end{tabular}

sub-population of patients with the highest risk of progression [16]. However, we found that only $10 \%$ of these patients progress to chronic dialysis thus highlighting the need to identify risk factors for such progression in order to target potential interventions to those who are most likely to benefit. Moreover, due to our study design, patients with severe AKI who did not recover renal function or those who initiated chronic dialysis within 90 days of discharge were excluded from our cohort; and therefore, the contribution of AKI to the progression to chronic dialysis is likely higher than our data suggests.

Similar to our report, studies by Stads et al. [17], Ishani et al. [18], and Lo et al. [3] have demonstrated the strong association between pre-existing CKD and the need for subsequent chronic dialysis. It is not surprising that preexisting CKD is one of the most important predictors modifying the relationship between AKI and progressive CKD as has been demonstrated in multiple studies [19-22]. The impact of even a modest acute insult to already compromised kidneys may be devastating. Although the biological mechanism linking CKD progression after AKI has not fully been elucidated, it has been postulated that the combination of acute endothelial injury leading to vascular dropout, and nephron loss followed by glomerular hypertrophy and the development of fibrosis may all play a role $[23,24]$. This may be more pronounced in patients with underlying CKD who may already possess a limited renal reserve, such that an episode of AKI may tip them into the need for chronic dialysis more easily than those without a background history of renal disease. Recognizing the 
limited performance of CKD diagnosis codes, we enhanced our capture of patients with underlying kidney disease by examining prior visits to a nephrologist, which we postulated as a reasonable surrogate for kidney disease. Both prior visits to a nephrologist and/or diagnosed CKD together capture the notion that patients who develop severe AKI with already-compromised kidney function are at substantially higher of accelerated and irreversible kidney dysfunction once the acute illness resolves.

As demonstrated by Chawla et al., we found that hypertension was another important predictor of chronic dialysis among AKI-D survivors [25]. Systemic hypertension is a potent contributor to the development of arteriosclerosis, tubulointerstitial fibrosis and glomerulosclerosis, all of which may hasten the decline in kidney function $[26,27]$. Patients with a history of hypertension may have underlying unrecognized CKD, despite having a "normal" serum creatinine level $[28,29]$. Subsequent renal injury imparted by an episode of AKI may not only unmask this underlying damage, but also lead to its acceleration.

The inverse association between liver disease and chronic dialysis was surprising given that these patients are prone to ongoing renal injury from changes in autoregulation due to arteriolar vasodilation and neuroendocrine changes associated with decompensated liver disease [30]. Perhaps, this group of patients underwent acute dialysis during their hospitalization as a bridge toward subsequent liver transplantation. Indeed, serum creatinine is a component of the Model for End-Stage Liver Disease (MELD) score which is used for organ allocation in patients with liver disease [31]. Severe AKI associated with liver disease is associated with extremely high mortality [32]. We speculate that the few individuals with liver disease who survived a hospitalization associated with AKI-D had a relatively lower burden of comorbidity. By the same token, the apparent "protective" association between mechanical ventilation on the index hospitalization and both chronic dialysis and all-cause mortality suggests that the sickest patients who received mechanical ventilation likely died during the hospitalization or shortly thereafter. Those fortunate to survive to 90 days following discharge were a selected group who by virtue of surviving the acute phase of their illness, were destined to have better outcomes.

Since the risk of death after an episode of AKI-D far outstrips that of chronic dialysis, predicting this outcome is also of vital clinical interest. As such, our study also delineated a number of predictors of post-AKI mortality including increasing age, a higher Charlson comorbidity score; the presence of heart failure, diabetes and dementia; as well as an inverse relationship with the receipt of mechanical ventilation. In line with previous work by Stads et al., preexisting CKD was strongly associated with death, which may relate to the link between CKD and cardiovascular disease $[17,33]$.
Our study has several strengths. Most notably, it is the first to determine the predictors of initiating chronic dialysis in a cohort of survivors of severe AKI using a competing risk approach. Although previous studies of AKI survivors have reported similar predictors, there are notable differences in methodology, case-mix and outcome ascertainment between these studies and ours [3,5,18,25,34]. Our use of a competing risk approach, may have avoided overestimating the cumulative incidence of the progression to chronic dialysis in survivors of severe AKI [35], and also gave us more robust effect estimates for our predictors [35]. Finally, our study was conducted in a jurisdiction with universal access to medical services and our databases reflect the entire population, maximizing generalizability. Though non-dialysis requiring CKD following AKI - is common and potentially problematic, we focused our attention on the extreme form of CKD, chronic dialysis, which has the most profound implications for quality of life and survival [2].

Our results have several potential implications. First, the identification of novel predictors of chronic dialysis in survivors of severe AKI may help improve the followup of these patients by selectively referring to nephrologists those patients who possess characteristics which place them at a high risk of progression. There is compelling data regarding the positive role that nephrologists may play in survivors of severe AKI; however, only a small proportion of severe AKI survivors are referred to a nephrologist for follow-up [2,11]. This may be related to limited access to nephrologists or an under-appreciation of the risk for progressive CKD following AKI. Alternatively, a select number of patients with pre-existing chronic kidney disease may already be followed by a nephrologist prior to their episode of AKI, and this continuity in care persists after the episode; thereby, obviating the requirement of a new referral. Second, knowledge of predictors of chronic dialysis may allow for the creation of a predictive model that can stratify AKI survivors at highest risk for progression to CKD for inclusion in clinical trials.

Several limitations merit consideration. First, our reliance on administrative codes for diagnoses and procedures limited our ability to better characterize the cohort and incorporate potentially vital data (eg, severity of acute illness, laboratory data) in to our models. In particular, the absence of pre-hospitalization laboratory data, most notable serum creatinine to estimate the glomerular filtration rate and information on proteinuria, is an important limitation $[22,25]$. As an alternative, we could only describe CKD using administrative coding, which is highly specific but poorly sensitive (median sensitivity $41 \%$; median specificity 98\%) [36], and by the surrogate of prior visits with a nephrologist which is an important shortcoming. Moreover, the administrative databases that we used did not contain data (laboratory and clinical data), which would have 
allowed us to determine illness severity (e.g., SOFA and APACHE scores). As these scores are useful predictors of outcome failure to account for them in our propensity score may have also contributed to confounding. Our inability to access preadmission laboratory data also precluded us from conducting more rigorous analyses with more robust measures of chronic kidney disease. Similarly, we had no way of evaluating the extent of kidney function recovery at the conclusion of the acute illness. Compromised residual kidney function following an episode of acute kidney injury is likely an important predictor of progression to chronic dialysis. Our definition for the receipt of chronic dialysis may have misclassified individuals who truly developed end-stage renal disease, but who died in the first 90 days after commencing chronic dialysis. However, our definition for the receipt of chronic dialysis is widely accepted, and has been used in multiple studies $[5,11]$. In addition, while it is interesting that greater global comorbidity, as expressed via the Charlson score, was associated with chronic dialysis and death, we could not identify which aspect(s) of the multicomponent Charlson score was most important. Ultimately, our predictive models showed limited discriminatory capacity suggesting that several factors that our datasets could not capture could have been relevant in anticipating important clinical outcomes following an episode of AKI. Moreover, we only examined a cohort of individuals who experienced the most severe form of AKI. In this regard, our findings may not be generalizable to individuals experiencing less severe yet much more common forms of AKI.

\section{Conclusions}

Using a competing risk model, we have demonstrated important predictors of progression to chronic dialysis in survivors of a hospitalization complicated by AKI requiring dialysis. Greater appreciation of the link between AKI and CKD is appropriately accompanied by calls for greater nephrology follow-up for AKI survivors. Our results identify patients with characteristics that associate with a high risk of kidney disease progression and death who should be targeted for closer post-discharge followup. Further studies to develop and validate a more robust predictive model, will help optimize outcomes of AKI survivors.

\section{Additional files}

Additional file 1: Candidate covariates.

Additional file 2: Diagnostic codes used in the study.

\section{Competing interests}

The authors declare that they have no competing interests.

\section{Authors' contributions}

$\mathrm{ZH}$, and RW were involved in the study concept, design and coordination, data analysis, and helped to draft the manuscript. SH, AXG, MTJ, CMB, SND, EM, and SS were involved in the analysis of the data, and helped to draft the manuscript. All authors read and approved the final manuscript.

\section{Acknowledgments}

This study was funded by a Research Chair in Continuity of Care and Patient Safety from the Canadian Patient Safety Institute and the Canadian Institutes of Health Research. These funding agencies had no role in the design and conduct of the study; collection, management, analysis, or interpretation of the data; or preparation, review, or approval of the manuscript.

\section{Author details}

'Division of Nephrology, St Michael's Hospital, University of Toronto, 61 Queen Street, 7th floor, M5C 2 T2, ON Toronto, Canada. ${ }^{2}$ Department of Medicine and Keenan Research Centre, Li Ka Shing Knowledge Institute of St Michael's Hospital, University of Toronto, Toronto, Canada. ${ }^{3}$ Department of Medicine, Mount Sinai Hospital, University of Toronto, Toronto, Canada. ${ }^{4}$ Institute of Clinical Evaluative Sciences, Kidney, Dialysis, Transplantation, London, Ontario, Canada. ${ }^{5}$ Division of Nephrology, London Health Sciences Centre, University of Western Ontario, London, Canada. ${ }^{6}$ Department of Medicine, Division of Nephrology, University of Calgary, Calgary, Alberta, Canada.

Received: 3 January 2014 Accepted: 3 July 2014

Published: 10 July 2014

\section{References}

1. Hsu RK, McCulloch CE, Dudley RA, Lo LJ, Hsu CY: Temporal changes in incidence of dialysis-requiring AKI. J Am Soc Nephrol 2013, 24(1):37-42.

2. Siew ED, Peterson JF, Eden SK, Hung AM, Speroff T, Ikizler TA, Matheny ME: Outpatient nephrology referral rates after acute kidney injury. J Am Soc Nephrol 2012, 23(2):305-312.

3. Lo LJ, Go AS, Chertow GM, McCulloch CE, Fan D, Ordonez JD, Hsu CY: Dialysis-requiring acute renal failure increases the risk of progressive chronic kidney disease. Kidney Int 2009, 76(8):893-899.

4. Wald R, Quinn RR, Adhikari NK, Burns KE, Friedrich JO, Garg AX, Harel Z, Hladunewich MA, Luo J, Mamdani M, Perl J, Ray JG: Risk of chronic dialysis and death following acute kidney injury. Am J Med 2012, 125(6):585-593.

5. Wald R, Quinn RR, Luo J, Li P, Scales DC, Mamdani MM, Ray JG: Chronic dialysis and death among survivors of acute kidney injury requiring dialysis. JAMA 2009, 302(11):1179-1185.

6. Fliser D, Laville M, Covic A, Fouque D, Vanholder R, Juillard L, Van Biesen W: A European Renal Best Practice (ERBP) position statement on the Kidney Disease Improving Global Outcomes (KDIGO) clinical practice guidelines on acute kidney injury: part 1: definitions, conservative management and contrast-induced nephropathy. Nephrology, dialysis, transplantation: official publication of the European Dialysis and Transplant Association European Renal Association 2012, 27(12):4263-4272.

7. Goldstein SL, Jaber BL, Faubel S, Chawla LS: AKI transition of care: a potential opportunity to detect and prevent CKD. Clin J Am Soc Nephrol 2013, 8(3):476-483.

8. Susantitaphong P, Cruz DN, Cerda J, Abulfaraj M, Alqahtani F, Koulouridis I, Jaber BL: World incidence of AKI: a meta-analysis. Clin J Am Soc Nephrol 2013, 8(9):1482-1493.

9. Charlson ME, Pompei P, Ales KL, MacKenzie CR: A new method of classifying prognostic comorbidity in longitudinal studies: development and validation. J Chronic Dis 1987, 40(5):373-383.

10. Quan H, Sundararajan V, Halfon P, Fong A, Burnand B, Luthi JC, Saunders LD, Beck CA, Feasby TE, Ghali WA: Coding algorithms for defining comorbidities in ICD-9-CM and ICD-10 administrative data. Med Care 2005, 43(11):1130-1139.

11. Harel Z, Wald R, Bargman JM, Mamdani M, Etchells E, Garg AX, Ray JG, Luo J, Li P, Quinn RR, Forster A, Perl J, Bell CM: Nephrologist follow-up improves all-cause mortality of severe acute kidney injury survivors. Kidney Int 2013, 83(5):901-908.

12. Wald R, Shariff SZ, Adhikari NK, Bagshaw SM, Burns KE, Friedrich JO, Garg AX, Harel Z, Kitchlu A, Ray JG: The association between renal replacement therapy modality and long-term outcomes among critically ill adults with acute kidney injury: a retrospective cohort study*. Crit Care Med 2014, 42(4):868-877. 
13. Go AS, Parikh CR, Ikizler TA, Coca S, Siew ED, Chinchilli VM, Hsu CY, Garg AX, Zappitelli M, Liu KD, Reeves WB, Ghahramani N, Devarajan P, Faulkner GB, Tan TC, Kimmel PL, Eggers P, Stokes JB: The assessment, serial evaluation, and subsequent sequelae of acute kidney injury (ASSESS-AKI) study: design and methods. BMC Nephrol 2010, 11:22.

14. Fine JP, Gray RJ: A proportional hazards model for the sub stitution of a competing risk. J Am Stat Assoc 1999, 94:496-509.

15. Wolbers M, Koller MT, Witteman JC, Steyerberg EW: Prognostic models with competing risks: methods and application to coronary risk prediction. Epidemiology 2009, 20(4):555-561.

16. Coca SG, Singanamala S, Parikh CR: Chronic kidney disease after acute kidney injury: a systematic review and meta-analysis. Kidney Int 2012, 81(5):442-448

17. Stads S, Fortrie G, van Bommel J, Zietse R, Betjes MG: Impaired kidney function at hospital discharge and long-term renal and overall survival in patients who received CRRT. Clin J Am Soc Nephrol 2013, 8(8):1284-1291.

18. Ishani A, Xue JL, Himmelfarb J, Eggers PW, Kimmel PL, Molitoris BA, Collins AJ: Acute kidney injury increases risk of ESRD among elderly. J Am Soc Nephrol 2009, 20(1):223-228.

19. Ishani A, Nelson D, Clothier B, Schult T, Nugent S, Greer N, Slinin Y, Ensrud KE: The magnitude of acute serum creatinine increase after cardiac surgery and the risk of chronic kidney disease, progression of kidney disease, and death. Arch Intern Med 2011, 171(3):226-233.

20. Hsu CY, Chertow GM, McCulloch CE, Fan D, Ordonez JD, Go AS: Nonrecovery of kidney function and death after acute on chronic renal failure. Clin J Am Soc Nephrol 2009, 4(5):891-898.

21. Pannu N, James M, Hemmelgarn BR, Dong J, Tonelli M, Klarenbach S: Modification of outcomes after acute kidney injury by the presence of CKD. Am J Kidney Dis 2011, 58(2):206-213.

22. Amdur RL, Chawla LS, Amodeo S, Kimmel PL, Palant CE: Outcomes following diagnosis of acute renal failure in U.S. veterans: focus on acute tubular necrosis. Kidney Int 2009, 76(10):1089-1097.

23. Basile DP: The endothelial cell in ischemic acute kidney injury: implications for acute and chronic function. Kidney Int 2007, 72(2):151-156.

24. Spurgeon-Pechman KR, Donohoe DL, Mattson DL, Lund H, James L, Basile DP. Recovery from acute renal failure predisposes hypertension and secondary renal disease in response to elevated sodium. Am J Physiol Renal Physiol 2007, 293(1):F269-F278

25. Chawla LS, Amdur RL, Amodeo S, Kimmel PL, Palant CE: The severity of acute kidney injury predicts progression to chronic kidney disease. Kidney Int 2011, 79(12):1361-1369.

26. Klag MJ, Whelton PK, Randall BL, Neaton JD, Brancati FL, Ford CE, Shulman NB, Stamler J: Blood pressure and end-stage renal disease in men. N Engl J Med 1996, 334(1):13-18.

27. Ravera M, Re M, Deferrari L, Vettoretti S, Deferrari G: Importance of blood pressure control in chronic kidney disease. J Am Soc Nephrol 2006, 17(4 Suppl 2):S98-S103.

28. Chawla LS, Kimmel PL: Acute kidney injury and chronic kidney disease: an integrated clinical syndrome. Kidney Int 2012, 82(5):516-524

29. Schainuck LI, Striker GE, Cutler RE, Benditt EP: Structural-functional correlations in renal disease. II. The correlations. Hum Pathol 1970, 1(4):631-641.

30. Arroyo V, Fernandez J: Management of hepatorenal syndrome in patients with cirrhosis. Nature reviews. Nephrology 2011, 7(9):517-526.

31. Chen YW, Chang CW, Wang TE, Wu CJ, Chen HH: Is an estimated glomerular filtration rate better than creatinine to be incorporated into the end-stage liver disease score? World J Hepatol 2012, 4(11):291-298.

32. Tsien CD, Rabie R, Wong F: Acute kidney injury in decompensated cirrhosis. Gut 2013, 62(1):131-137.

33. Levey AS, Beto JA, Coronado BE, Eknoyan G, Foley RN, Kasiske BL, Klag MJ, Mailloux LU, Manske CL, Meyer KB, Parfrey PS, Pfeffer MA, Wenger NK, Wilson PW, Wright JT Jr: Controlling the epidemic of cardiovascular disease in chronic renal disease: what do we know? What do we need to learn? Where do we go from here? National Kidney Foundation Task Force on Cardiovascular Disease. Am J Kidney Dis 1998, 32(5):853-906.

34. James MT, Ghali WA, Tonelli M, Faris P, Knudtson ML, Pannu N, Klarenbach SW, Manns BJ, Hemmelgarn BR: Acute kidney injury following coronary angiography is associated with a long-term decline in kidney function. Kidney Int 2010, 78(8):803-809.

35. Noordzij M, Leffondre K, van Stralen KJ, Zoccali C, Dekker FW, Jager KJ: When do we need competing risks methods for survival analysis in nephrology? Nephrol Dial Transplant 2013, 28(11):2670-2677.

36. Vlasschaert ME, Bejaimal SA, Hackam DG, Quinn R, Cuerden MS, Oliver MJ, lansavichus A, Sultan N, Mills A, Garg AX: Validity of administrative database coding for kidney disease: a systematic review. Am J Kidney Dis 2011, 57(1):29-43.

doi:10.1186/1471-2369-15-114

Cite this article as: Harel et al:: Predictors of progression to chronic dialysis in survivors of severe acute kidney injury: a competing risk study. BMC Nephrology 2014 15:114.

\section{Submit your next manuscript to BioMed Central and take full advantage of:}

- Convenient online submission

- Thorough peer review

- No space constraints or color figure charges

- Immediate publication on acceptance

- Inclusion in PubMed, CAS, Scopus and Google Scholar

- Research which is freely available for redistribution

Submit your manuscript at www.biomedcentral.com/submit
C) BioMed Central 